6 PHLS Report, British Medical fournal, 1971, 3, 382.

7 Pittman, F E, and Hennigar, J B, Archives of Pathology, 1974, 97, 155

${ }^{8}$ Morrey, B, and Wolma, F J, Southern Medical fournal, 1972, 65, 678.

${ }^{9}$ Brooke, $\mathrm{M} \mathrm{M}$, and Goldman, M, Fournal of Laboratory and Clinical Medicine, 1949, 34, 1554

10 Parelkar, S N, and Stamm, W P, Transactions of the Royal Society of Tropical Medicine and Hygiene, 1973, 67, 659

${ }^{11}$ Krupp, I M, and Powell, S J, American fournal of Tropical Medicine and Hygiene, 1971, 20, 421.

12 Stamm, W P, Ashley, M J, and Parelkar, S N, Transactions of the Royal Society of Tropical Medicine and Hygiene, 1973, 67, 211.

13 Stamm, W P, and Phillips, E A, Transactions of the Royal Society of Tropical Medicine and Hygiene, 1977, 71, 490.

14 Poltera, A A, and Owor, R, East African Medical fournal, 1973, 50, 344.

${ }_{15}$ Parelkar, S N, Stamm, W P, and Hill, K R, Lancet, 1971, 1, 212.

${ }^{16}$ The Times, 15 March, 1978.

\section{Audiometry in industry}

Occupational deafness ${ }^{1}$ has been a prescribed disease in the United Kingdom in certain industries since 1975. The diagnosis is made on audiometric evidence supported by a consultant ear, nose, and throat surgeon's opinion that the loss of hearing has been induced by noise. In recent years, too, audiometric monitoring of workers exposed to occupational noise has been achieving greater importance. ${ }^{2}$ These audiograms may show threshold changes in hearing of a pattern specific for noiseinduced damage. Studies in working populations have shown that some individuals have so-called sensitive ears ${ }^{3}$ that deteriorate rapidly in the presence of levels of noise which have no effect on the rest of the population. This is hardly a surprising finding, for most biological characteristics show variability over a considerable range.

The best way of preventing occupational deafness is for workers not to be exposed to noise. Ideally this is done by engineering design and enclosure at the source of noise; but in the short term often the only practical solution is the use of hearing protectors. At its best this method depends on full co-operation by the employee and at its worst may be quite useless-and give a false sense of security.

A study by Burns and Robinson ${ }^{4}$ in 1970 first showed that the degree of occupational hearing loss could be related to exposure to noise in mathematical terms. From this study grew the Department of Employment's code of practice for reducing the exposure of employed persons to noise, ${ }^{5}$ which recommended a maximum permissible level of 90 decibels $(\mathrm{dB}(\mathrm{A}))$ over an eighthour working day. This threshold was designed to protect $99 \%$ of the exposed population from hearing loss induced by noise. Nevertheless, Tempest $^{6}$ has recently questioned whether the figure was correctly set, and other authorities have recommended a maximum permissible level of $85 \mathrm{~dB}(\mathrm{~A})$. The practical implications of such a reduction have caused serious concern in industry, which has seen the increased cost of introducing equipment to meet this standard as crippling to the employer while making little practical difference to the protection of the individual.

There has been considerable controversy 28 about the routine use of audiometry in industry. A working group set up by the Industrial Health Advisory Committee (later incorporated into the Health Safety Executive) in 1975 has now prepared a discussion document Audiometry in Industry ${ }^{9}$ as a basis for guidance on indications for an audiometric programme and on suitable techniques; comment is invited by February 1979. The committee has recommended that audiometry should be mandatory for all those exposed to a noise level of $105 \mathrm{~dB}(\mathrm{~A})$ equivalent sound level for an eight-hour day: it did not consider a programme necessary where the exposure does not exceed $85 \mathrm{~dB}(\mathrm{~A})$. At levels between 85 and $105 \mathrm{~dB}(\mathrm{~A})$ other factors should be taken into account in the decision on whether or not to have a routine programme.

The committee also recommended the degrees of hearing loss which should be taken as justifying warnings to employees. These levels are related to age, but at the lower limit employees would be "warned of the status of the audiogram and recommended to take precautionary measures to preserve their hearing," while at the higher level the employee would be referred to an ear, nose, and throat surgeon.

The American Academy of Ophthalmology and Oto- $\stackrel{\mathbb{D}}{\circ}$ laryngology has taken $27 \mathrm{~dB}$ averaged over $0 \cdot 5,1,2, \mathrm{KHz}$ as its measure of the "slight impairment" level (at which compensa- $\overrightarrow{\vec{F}}$ tion begins). Compensation is payable by the DHSS if there is a $\overrightarrow{0}$ hearing loss of above $50 \mathrm{~dB}$, averaged over 1,2 , and $3 \mathrm{KHz}$. The $\frac{c}{\sigma}$ warning levels set out in the discussion document are generally $\bar{\omega}$ at lower thresholds than this; the committee seems to have set $\vec{\nabla}$ its level as one at which changes are detectable on testing but not subjectively to the individual.

Clearly it is important to know whether any test can predict $\vec{\circ}$ which persons will develop the most rapid deterioration in hearing. If a high-risk group could be identified they should be excluded from noisy occupations. Howell ${ }^{10}$ recently studied the $\bar{\partial}$ changes observed in an eight-year period among steel workers 3 . aged from 15 to 54 at the time of initial audiometry. They were ? grouped according to the level of exposure to noise from their occupational histories and from assessments of their actual $\underset{\omega}{\omega}$ working conditions-which could only be approximations. There $\omega_{\infty}$ was no evidence that workers with high initial threshold levels of hearing were any more likely to have rapid hearing loss than their colleagues with more normal initial audiograms.

At present, therefore, routine pre-employment audiometry $v$ cannot be shown to have any predictive value-but it can detect persons with existing deficits who would suffer actual hearing loss if they deteriorated. ${ }^{11}$ The challenge remaining for research $\stackrel{\oplus}{\rightarrow}$ workers is to devise a cheap and practical test to detect the $\vec{\theta}$ potential employee with a sensitive ear and thus exclude him $\infty$ from employment that would be harmful.

1 Industrial Injuries Advisory Council, Occupational Deafness. London, HMSO, 1973 .

2 Pelmear, P L, fournal of the Society of Occupational Medicine, 1973, 23, 22.

3 Burns, W, and Robinson, D W, fournal of the Society of Occupational Medicine, 1973, 23, 86.

4 Burns, W, and Robinson, D W, Hearing and Noise in Industry. London, HMSO, 1970.

${ }^{5}$ Department of Employment, Code of Practice for Reducing the Exposure of Employed Persons to Noise. London, HMSO, 1972.

6 Tempest, W, Annals of Occupational Hygiene, 1978, 21, 51.

7 Atherley, G R C, Duncan, J S, and Williamson, K S, fournal of the Society of Occupational Medicine, 1973, 23, 19.

${ }^{8}$ Atherley, G R C, Merriman, R J, and Phillips, M R, in Proceedings of a Symposium on Health Screening. London, Society of Occupational Medicine, 1977.

${ }^{9}$ Health and Safety Executive Working Group, Audiometry in Industry. London, HMSO, 1978

10 Howell, R W, British fournal of Industrial Medicine, 1978, 35, 27.

11 Acton, W I, Annals of Occupational Hygiene, 1977, 20, 387.

\section{Dyspnoea in normal pregnancy}

Claude Bernard's famous dictum ${ }^{1}$ about the static equilibrium of the milieu intérieur may have hindered rather than advanced $\Phi$ our understanding of fundamental physiological and biochemical processes-for we are still reluctant to acknowledge that the equilibrium may be set at different levels at different times in the same organism. ${ }^{2}$ Pregnancy offers some good examples. The blood concentrations of urea may fall by $30 \%$, creatinine $\unrhd$ by $40 \%$, plasma osmolality by $10 \mathrm{mmol}$ per $\mathrm{kg}$, and the haemoglobin by $2 \mathrm{~g}$ per dl by the 12th week; and these and other 8 comparable changes are compatible with normal, healthy fetal and maternal life. In the face of such physiological adaptation to pregnancy most women accept with equanimity such inconveniences as nausea and vomiting in the early months, breathlessness, oedema, and a gain in weight. The difficulty for the patient and her doctor is to decide when any of these symptoms 
or signs have passed beyond the physiological boundaries and become pathological.

Dyspnoea in a young woman who is not pregnant immediately suggests some underlying disease, so that understandably many women (and their doctors) find it difficult to accept some breathlessness as a normal event. But in practice many healthy pregnant women with no history of cardiorespiratory disease do complain of dyspnoea. Milne $e t a l^{3}$ studied the incidence, severity, and time course of dyspnoea in 62 such women. Nine were aware of dyspnoea during the first trimester, 31 by the 19 th week, and 46 by the 31 st week.

These results point to a physiological rather than a mechanical cause. The newborn infant (and presumably the fetus) is more sensitive to carbon dioxide than the adult, ${ }^{4}$ and Hytten ${ }^{5}$ has suggested that the fetus "resets" the mother's respiratory centres so that she overbreathes from early pregnancy, reducing her $\mathrm{PCO}_{2}$ from about $40 \mathrm{~mm} \mathrm{Hg}$ to $30 \mathrm{~mm} \mathrm{Hg}$ or even less. This offers the fetus a favourable carbon dioxide transport systembut for the mother, accustomed to breathing with an alveolar $\mathrm{PCO}_{2}$ of over $40 \mathrm{~mm} \mathrm{Hg}$, the ventilatory response to the lower $\mathrm{PCO}_{2}$ level may appear "inappropriate," and according to Campbell and Howell ${ }^{6}$ it is this that gives rise to the sensation of dyspnoea.

The lowering of the $\mathrm{PCO}_{2}$ by overbreathing leads to other changes in maternal homoeostasis. The accompanying drop in plasma osmolality would normally be followed by a check in the secretion of vasopressin and a substantial diuresis. That early pregnancy is not associated with a continuous diuresis suggests that the osmoreceptors have been reset to maintain the new low level of osmolality in the same way as the respiratory centres are reset to accept the new low level of $\mathrm{PCO}_{2} .{ }^{5}$

This example of adaptation to pregnancy illustrates the dominant position of the fetus and its ability to reach out to alter the balance of the mother's central control mechanisms. A little dyspnoea is a small price to pay for helping to secure a favourable environment for the fetus, and the wonder is that such fundamental changes in the milieu intérieur cause relatively small upset to the mother's wellbeing. In practical terms it is important that the doctor should exclude any underlying disease before he reassures the patient and offers a simple, physiological explanation for her changed breathing pattern.

\footnotetext{
${ }^{1}$ Bernard, C, Leçons sur les Phénomènes de la vie Communs aux Animaux et aux Végétaux. Paris, Libraire J Ballière et Fils, 1878.

${ }^{2}$ Leitch, I, Proceedings of the Nutrition Society, 1957, 16, 38.

3 Milne, J A, Howie, A D, and Pack, A I, British fournal of Obstetrics and Gynaecology, 1978, 85, 260.

${ }^{4}$ Cross, K W, Hooper, J D M, and Oppé, T E, Fournal of Physiology, 1953, 119, 11.

${ }^{5}$ Hytten, F E, Acta Paediatrica Academiae Scientiarum Hungaricae, 1976, $17,1$.

${ }^{6}$ Campbell, E J M, and Howell, J B L, British Medical Bulletin, 1963, 19, 36.
}

\section{Chronic effects of alcohol}

Even in persons eating a nutritionally adequate diet a high intake of alcohol causes fatty infiltration of the liver, whose degree is proportional to the amount consumed. ${ }^{12}$ Baboons fed alcohol also develop fatty liver and, if alcohol feeding is continued for several months, they progress to alcoholic hepatitis and cirrhosis morphologically similar to that seen in man. ${ }^{3} \mathrm{~A}$ wealth of further epidemiological evidence links diseases of the liver, pancreas, and heart to excessive alcohol consumption. ${ }^{45}$

In clinical practice it is far more difficult to relate the severity of these lesions to the amount of alcohol consumed. Because of the social stigma attached to alcoholism, especially in women, patients often minimise their true intake or attempt to conceal their problem completely. Furthermore, an individual's consumption of alcohol will vary according to its availability and cost and his income. Demotion or unemployment may reduce his intake-or make him switch to less expensive forms of alcohol, possibly supplemented by methylated spirits. Not surprisingly, most research which has attempted to measure alcohol intake and relate it to human disease has come from wine-producing countries, where alcohol is cheap and a high intake more socially acceptable than in Britain.

Liver disease is of paramount importance in chronic alcoholism, and because of the wide range of possible damage and the relative ease of diagnosis attempts to measure the toxic dose of alcohol have mainly referred to its effect on the liver. Lelbach ${ }^{6}$ studied 319 men admitted to an alcohol detoxication unit from 1960 to 1963 in whom the history of alcohol intake was regarded as reliable. All had undergone liver biopsy. The mean daily alcohol intake of those with normal livers was $139.5 \mathrm{~g}$ (equivalent to eight pints of beer, a bottle of sherry, or two-thirds of a bottle of spirits), whereas patients with fatty liver, chronic hepatitis, and cirrhosis had mean intakes of $172 \mathrm{~g}, 203.5 \mathrm{~g}$, and $245.5 \mathrm{~g}$ respectively. No patient with cirrhosis had an average daily intake of less than $190 \mathrm{~g}$.

Such a positive association between amount consumed and degree of liver damage is strong evidence in support of a direct hepatotoxic effect of alcohol. Nevertheless, more recent work indicates that some patients, especially women, may develop advanced liver disease after consuming much less than these amounts, raising the possibility that genetic or immunological factors may lower the threshold dose of alcohol required to initiate damage or, once damage has occurred, favour its progression. Thus Pequignot, ${ }^{7}$ comparing the alcohol intake of patients with cirrhosis with that of a random sample of the population, concluded that there is an increased prevalence of cirrhosis when daily alcohol consumption exceeds $60 \mathrm{~g}$ for men and $20 \mathrm{~g}$ for women. As the group with cirrhosis included some with non-alcoholic disease, these levels will be underestimates.

A recent English study ${ }^{8}$ has confirmed that women seem more susceptible to alcoholic liver disease: despite there being a lower proportion of women consuming more than $150 \mathrm{~g}$ alcohol per day, their liver disease was more severe and they showed a definite increase in the incidence of smooth muscle and antinuclear antibodies and higher mean IgG and IgM concentrations. Another finding of interest was the higher prevalence of the histocompatibility antigen HLA-B8 in alcoholics with cirrhosis than in those with fatty change only. ${ }^{9}$ Patients with cirrhosis tended to be regular drinkers, while in those with less severe histological abnormalities an intermittent pattern of heavy drinking was more common. ${ }^{10}$

Both acute and chronic pancreatitis are associated with heavy alcohol consumption, and the proportion of patients who are alcoholic seems to be increasing. ${ }^{11}{ }^{12}$ Unfortunately, we have comparatively few data on intake. Sarles et $a l^{13}$ found that the mean daily alcohol intake in 55 patients with chronic calcific pancreatitis was $175 \mathrm{~g}$; only one patient abstained from alcohol. In an international survey of chronic pancreatitis ${ }^{14}$ the mean daily alcohol intake was about $150 \mathrm{~g}$. By contrast, acute alcoholic pancreatitis tends to be a disease of "spree" drinkers, most commonly young men, rather than of chronic alcoholics. ${ }^{11}$

The effects of alcohol on the heart present an interesting paradox. On the one hand, alcoholic cardiomyopathy is a wellestablished though uncommon sequel to chronic alcoholism; on the other, the incidence of ischaemic heart disease seems to be less in people who drink than in total abstainers. Alcoholic cardiomyopathy is seen most often in patients who have drunk heavily (over one-third of a bottle of spirits- $80 \mathrm{~g}$ alcohol-per day) for at least five years, ${ }^{15}$ but nutritional deficiency may also be relevant-though frank deficiency of thiamine is uncommon in Western countries.

In both the Kaiser-Permanente ${ }^{16}$ and Framingham studies, ${ }^{17}$ the incidence of ischaemic heart disease was lower in people with a moderate intake of alcohol, and a study from Hawaii of middle-aged Japanese men showed an even stronger negative correlation. ${ }^{18}$ The cumulative incidence of ischaemic heart disease over six years showed a significant trend to lower levels 